Few will quarrel with the quality of the contents, but many will undoubtedly consider that the authors should not have included so much material that is more appropriate to the $S .3$ year. In this way a fuller treatment and coverage could have been given to the rest.

There is a great need for text-books having a specific purpose, and in this case there is fairly general agreement as to the material appropriate for inclusion in an S.2 course in electrical engineering. Such text-books would have a beneficial effect on the standard of lecturing as they should eliminate or reduce the use of the chalkboard and the corresponding copying of notes by students.

In any revision of the text the author might usefully consider whether the mathematical approach is always essential as it is possible that with this type of student this may disguise or confuse the physical principles. There is some doubt whether the academic standard is not above the average reader for whom the book is intended. In particular, the approach to alternating currents could well be based entirely on the use of the rotating vector, thus leaving the trigonometrical method an applied exercise for the mathematics course.

The book is well printed on good quality paper with an attractive format and good binding. It is distinctly readable and is strongly recommended. P. F. SOPER

\section{VOLTAGE STABILIZATION}

Voltage Stabilized Supplies

Basic Principles, Characteristics and Applications. By Dr. F. A. Benson. Pp. 370. (London: Macdonald and Co. (Publishers), Ltd., 1957.) 50s. net.

HIS book, as stated by the author in his preface, is based on a monograph published in 1950 and most of the material of this monograph (including ninety-three figures) is reproduced with little alteration. Additional material has, of course, been added. Like the monograph the book does not deal with electromechanical devices or with the control of generators.

A large proportion (one-third) is devoted to glowdischarge tubes and their circuits. This is to be expected in view of the author's work on this subject. It would have been helpful to include manufacturers' data on the many tubes considered and one tends to be confused by the use of $C V$-numbers for valves and tubes in one section and civilian numbers in other sections. A large number of figures and graphs are given on discharge tubes but it is difficult to come to conclusions. Explanations of the practical importance of these results and suggestions for suitable tubes for various purposes would have been helpful. A most useful chapter is included on corona discharge tubes.

The two chapters dealing with thermionic valve stabilizers would be improved by the inclusion of more design data on 250-500 $\mathrm{V}$. stabilizers and by the use of modern valves and tubes in the circuits and performance calculations. It should be noted (p. 169) that a shunt stabilizer valve is available for $20 \mathrm{kV}$.

A most useful chapter is devoted to battery reference sources but the work on bridges in Chapter 10 might also have been included, with advantage, in this chapter. The next chapter deals adequately with magnetic stabilizers.
The final chapter (85 pages) deals with bridge circuits, saturated diodes and miscellaneous circuits. Fig. 205 appears to be so nearly identical with Fig. 202 as to be scarcely worth including. The chapter covers an extensive range of circuits but sections tend to read as a list of published works.

Heading of the right-hand page with the title of the chapter or subject of the page would be a great improvement.

More than a thousand references are included from numerous sources and this forms a most valuable portion of the book.

Dr. Benson has been most successful in producing a well-written, clearly illustrated and valuable book for the engineer and research worker, but not quite so successful in producing a book suitable for the student.

G. N. Patchett

\section{THE SCYTHIANS}

\section{The Scythians}

By Tamara Talbot Rice. (Ancient Peoples and Places.) Pp. 255+62 plates. (London: Thames and Hudson, Ltd., 1957.) 21s. net.

ITTLE has been written in English about the 1 Scythians since the late Sir Ellis Minns's great works, the second of which was published in 1942. Yot these people, who appeared suddenly as nomadic folk in the plains to the north of the Black Sea and who vanished just as suddenly as a result of the incursions of the Sarmatians, extended their influence during the period of their dominance (c. 700 B.c. to c. A.D. 50) well beyond the area of their homelands, and the characteristic art they developed still remains a joy to all art lovers to-day. It is not certain where they were cradled, the most popular suggestion being the Altai steppes, but they first appear before us as horse-breeding nomads, only now and then developing a village life. They seem to have erected no temples and we know little about their religious ideas. But they attached enormous importance to the burial of the dead and their tombs are filled with the richest of funeral furniture. Naturally, for nomad peoples wandering over vast plains, the horse was of supreme importance and value, and nearly always horses were slaughtered and buried with the dead man. There is one case where no less than 400 were so destroyed. Some of these animals were not without blemish-one could scarcely expect the living to give up all their best horses for this purpose. However, they frequently did.

Mrs. Talbot Rice has written a volume on the Scythians in a new series, "Ancient Peoples and Places", which is under the editorship of Dr. Glyn Daniel. It is an exceedingly good and read. able book and is exceptionally well illustrated, both with line blocks in the text and with no less than thirty-two full pages of illustrations at the end of the work. Naturally the illustrations are concerned with the art, but one or two of the line draw. ings are devoted to such subjects as the plan of the Kostromskaya burial and a section at the same site. The book will fill a gap, and such a work is overdue. Doubtless the specialist in the prehistory of those regions will regret many details which the size of the volume has made it necessary to omit. But the general archæologist and the interested reader will welcome Mrs. Talbot Rice's book.

M. C. BURK ITT 